\title{
Design of a High Voltage Bidirectional DC-DC Converter for Driving Capacitive Incremental Actuators usable in Electric Vehicles (EVs)
}

Thummala, Prasanth; Zhang, Zhe; Andersen, Michael A. E.; Maksimovic, Dragan; Sarban, Rahimullah

\section{Published in:}

Proceedings of IEEE International Electric Vehicle Conference (IEVC),

Link to article, DOI:

10.1109/IEVC.2014.7056132

Publication date:

2014

Document Version

Early version, also known as pre-print

Link back to DTU Orbit

Citation (APA):

Thummala, P., Zhang, Z., Andersen, M. A. E., Maksimovic, D., \& Sarban, R. (2014). Design of a High Voltage Bidirectional DC-DC Converter for Driving Capacitive Incremental Actuators usable in Electric Vehicles (EVs). In Proceedings of IEEE International Electric Vehicle Conference (IEVC), IEEE Press. https://doi.org/10.1109/IEVC.2014.7056132

\section{General rights}

Copyright and moral rights for the publications made accessible in the public portal are retained by the authors and/or other copyright owners and it is a condition of accessing publications that users recognise and abide by the legal requirements associated with these rights.

- Users may download and print one copy of any publication from the public portal for the purpose of private study or research.

- You may not further distribute the material or use it for any profit-making activity or commercial gain

- You may freely distribute the URL identifying the publication in the public portal 


\section{Design of a High Voltage Bidirectional DC-DC Converter for Driving Capacitive Incremental Actuators Usable in Electric Vehicles (EVs)}

\author{
Prasanth Thummala, Zhe Zhang, \\ Michael A. E. Andersen \\ Department of Electrical \\ Engineering \\ Technical University of Denmark \\ DK-2800 Kongens Lyngby, \\ Denmark \\ pthu@elektro.dtu.dk
}

\author{
Dragan Maksimovic \\ Colorado Power Electronics Center \\ Department of Electrical, Computer, \\ and Energy Engineering \\ University of Colorado at Boulder \\ Boulder, Colorado, USA-80309 \\ maksimov@colorado.edu
}

\author{
Rahimullah Sarban \\ LEAP Technology \\ Science and Technology Park, \\ Diplomvej 381, \\ DK-2800 Kongens Lyngby, \\ Denmark \\ rahim@leaptechnology.com
}

\begin{abstract}
This paper presents the design of a low input (24 V) and variable high output voltage $(0-2.5 \mathrm{kV})$ bidirectional dc-dc converter for driving a capacitive actuator. The topology is a digitally controlled bidirectional flyback converter with a variable frequency control. The objective is, to design the converter for efficiently charging and discharging the capacitive actuator from $0 \mathrm{~V}$ to $2.5 \mathrm{kV}$ and vice versa, respectively. The converter is used to drive a dielectric electro active polymer (DEAP) based capacitive incremental actuator, which has the potential to be used in automotive (e.g., EVs), space and medical industries. The design of the bidirectional flyback converter to charge and discharge a $400 \mathrm{nF}$ capacitive actuator is presented, when $4 \mathrm{kV}$ and $4.5 \mathrm{kV}$ high voltage MOSFETs are used on the secondary high voltage side. The experimental results and efficiency measurements of the converter with the proposed design are provided.
\end{abstract}

Keywords-switch mode power converters, electric vehicles, capacitive actuators, high voltage, dc-dc converters

\section{NOMENCLATURE}

$A_{c}$

$B_{\max C} / B_{\max D}$

Cross sectional area of the core

Maximum flux density during charge/discharge process

$C_{\text {in }} / C_{\text {load }}$ Input capacitance/Load or actuator capacitance

$D_{2} / D_{b}$ High voltage $(5 \mathrm{kV})$ diode which conducts during charge/discharge process

$D_{b 1} / D_{b 2}$

$D_{\text {onC,min }}$

$D_{\text {offC, } \max }$

$D_{\text {onD, } \max }$

$f_{s w C} / f_{s w D}$

$i_{\text {in }} / i_{p} / i_{s}$

$I_{p p k C} / I_{s p k D}$

$I_{D 2} / I_{D b}$

$I_{M 2}$

$L_{m p} / L_{m s}$

Body diodes of MOSFET $M_{1} / M_{2}$

Minimum on-duty cycle of $M_{1}$

Maximum off-duty cycle of $M_{1}$

Maximum on-duty cycle of $M_{2}$

Switching frequency during charge/discharge process

Input/Primary/Secondary current

Primary charging peak current/secondary discharging peak current

Rated average current of diode $D_{2} / D_{b}$

Rated average current of MOSFET $M_{2}$

Primary/secondary magnetizing inductance $n$
$L_{l k p} / L_{l k s}$

$M_{1}$

$M_{2}$

$N_{p} / N_{s}$

$R_{p} / R_{S}$

$T_{c h}$

$t_{\text {onC }} / t_{\text {offC }}$

$t_{\text {onD }} / t_{\text {offD }}$

$V_{\text {in }} / \Delta V_{\text {inD }}$

$V_{o, \max }$

$V_{\text {outC }} / V_{\text {outD }}$

$V_{M 1} / V_{M 2}$

$V_{D 2} / V_{D b}$

$V_{o n D 2} / V_{o n D b}$

$V_{B V M 1} / V_{B V M 2}$

$V_{B V D 2}$

$\beta_{M 1} / \beta_{M 2} / \beta_{D 2}$

$\eta$

Leakage inductance of transformer referred to primary side/secondary side Low voltage MOSFET

High voltage $(4 \mathrm{kV} / 4.5 \mathrm{kV})$ MOSFET

Turns ratio of the transformer from secondary to primary

Number of primary/secondary turns

Primary/Secondary dc resistance of transformer Charging time to reach the target output voltage On-time/Off-time of $M_{1}$ during charge process On-time/Off-time of $M_{2}$ during discharge process

Input voltage/Increment in the input voltage during discharge process

Maximum or target output voltage

Variable load voltage during charge process $(0$ $\mathrm{V}-2.5 \mathrm{kV}) /$ discharge process $(2.5 \mathrm{kV}-0 \mathrm{~V})$

Drain-to-source voltage of MOSFET $M_{1} / M_{2}$

Reverse voltage across high voltage diode $D_{2} / D_{b}$

Voltage drop of high voltage diode $D_{2} / D_{b}$

Breakdown voltage of MOSFET $M_{1} / M_{2}$

Breakdown voltage of high voltage diode $D_{2}$ (or $D_{b}$ )

Margin factor $(<1)$ for $V_{B V M 1} / V_{B V M 2} / V_{B V D 2}$

Power efficiency of the converter

\section{INTRODUCTION}

Dielectric electro active polymer (DEAP) is an emerging smart material technology that has experienced substantial growth and has gained significant attention over the last decade [1]-[3]. The DEAP material is a very thin $(\sim 40 \mu \mathrm{m})$ incompressible elastomer film having a compliant electrode layer on both sides [4]-[6]. The basic operation of the DEAP is the reduction in the polymer's thickness and increase in its area, due to an applied electric field. DEAP, when utilized as linear actuators (Fig. 1), has the potential to be an effective replacement for many conventional actuators. Several applications of DEAP actuators are discussed in [7]-[14]. 


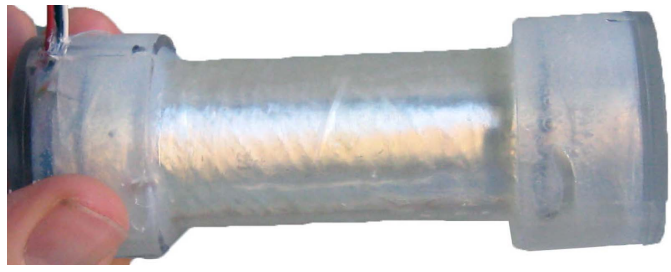

Fig. 1. A prototype of linear DEAP actuator.

Linear actuators are increasingly used in the automotive industry, for providing various functions. Some of them include, a piezo actuator drive (PAD) to control the door of a car [15], electric actuators to control and move the headlights of vehicles [16], linear motors to replace the conventional shock absorbers in cars [17] (see Fig. 2), digital linear actuators to adjust the air flow in the throttle by pass valve [18], and actuators for the central locking system [19]. However, some of these linear actuators can be very heavy, inefficient, rigid, and can have limited performance (force, stroke, and speed).

Therefore, DEAP actuators have their highest value proposition in automotive and specifically for electric vehicles (EVs) where system efficiency is of highest importance. Replacement of conventional actuators with DEAP actuators is able to provide the following advantages for electric vehicles:

1. DEAP is seven times lighter than copper and steel by which the conventional actuators are made of. Reducing the weight in electric vehicles can result in better overall efficiency.

2. DEAP actuators are capacitive devices, i.e., a large portion of the energy is reactive and can be harvested and reused in cyclic motions. This will require less energy from the main power source of an electric vehicle, once again increasing its efficiency.

3. DEAP actuators are entirely made of rubbery material which is inherently tolerant to shock and vibration which exist in every vehicle. Moreover, a DEAP actuator does not incorporate any moving and sliding parts such as bearings, gearing and similar. All these characteristics result in improved lifetime, cost, and efficiency.

4. DEAP actuators can be configured to provide incremental motion, thus overcoming the inherent size-to-stroke implications of conventional linear actuators, where the stroke is limited by their size. In incremental mode, DEAP actuators are several orders of magnitude shorter in its length compared to the stroke they provide. This will once again reduce the size and weight of the actuation mechanism resulting in vehicle efficiency.

The DEAP incremental actuator concept [20] consists of two grippers (to enable gripping operation) and an extender (to move the grippers), see Fig. (3). These grippers connect with the extender using the mechanical structures, so the incremental actuator is equivalent to three independent capacitive actuators with electrical isolation between them.

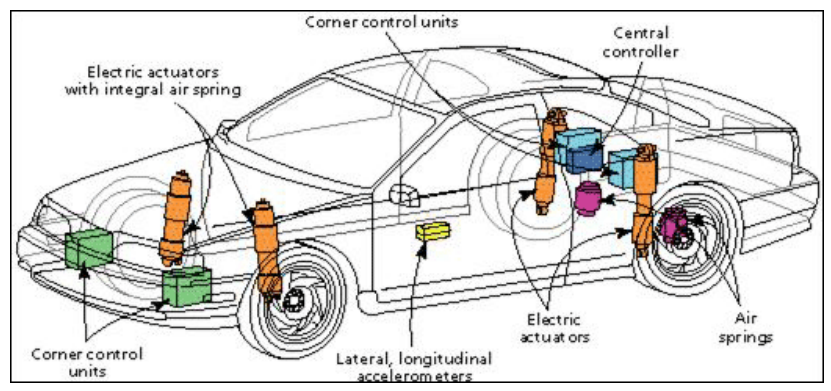

Fig. 2. Replacing the shock absorbers in a car with linear motors [17].

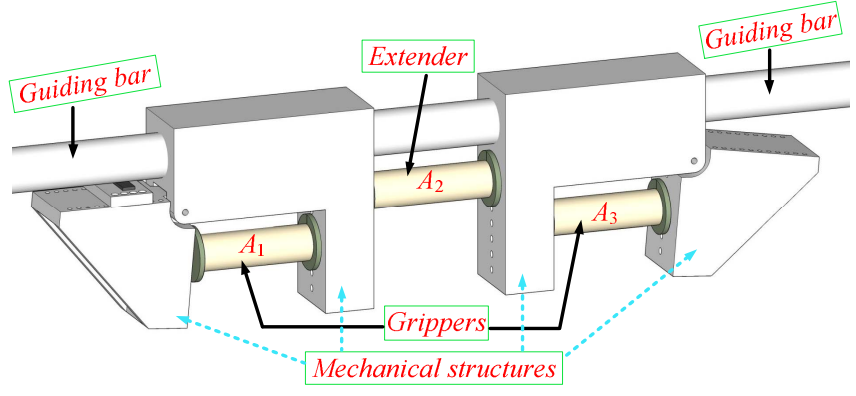

Fig. 3. Conceptual diagram of the DEAP incremental actuator.

Due to the requirement of high electric field strength (40$60 \mathrm{~V} / \mu \mathrm{m})$, DEAP actuator needs high voltage $(2.5 \mathrm{kV})$ to fully elongate the actuator. Hence, high voltage dc-dc converters are needed to drive the DEAP actuators. The flyback converter is suitable for high voltage and low power applications due to its simple structure and low component count [21]. Efficiency optimization of the flyback converter for wide range of operating conditions is discussed in [22]. Control algorithms for optimal-flyback charging of a capacitive load have been proposed in [23]. High voltage switch-mode power supplies for charging the capacitive loads have been implemented in [24], [25]. The bidirectional flyback converters are proposed in [26]-[28] to transfer the power in both directions. Prior work on the high voltage drivers for the DEAP actuators demonstrated a low voltage piezoelectric transformer based DEAP solution, and it was inserted inside a coreless DEAP actuator [29], and a bidirectional flyback converter topology to drive the PolyPower Push Inlastor DEAP actuator [30]. In [31] an efficiency optimization technique is proposed for a bidirectional flyback converter used to drive capacitive actuator. Several transformer winding architectures have been investigated in [32] for the high voltage capacitor charge and discharge application. A digital control technique to achieve the valley switching in a bidirectional flyback converter is proposed in [33]. This paper focuses on the power stage design of a bidirectional flyback converter, which is used to drive the incremental DEAP actuator as shown in Fig. 3.

This paper is organized as follows: Section II describes the converter design considerations. Section III provides the experimental results followed by the conclusions in Section IV. 


\section{BIDIRECTIONAL DC-DC CONVERTER DESIGN CONSIDERATIONS}

The schematic of the bidirectional flyback converter is shown in Fig. 4. Due to very high reverse recovery time of the high voltage (HV) MOSFET $M_{2}$ (e.g., $2.6 \mu$ s for a $4 \mathrm{kV}$ MOSFET), a blocking diode $D_{b}$ is added in series with it. The converter design considerations are discussed in this section. Specifications of the converter and power stage components are provided in Tables I and II, respectively. The main focus of this paper is the design of flyback transformer, as it a critical component in the converter.

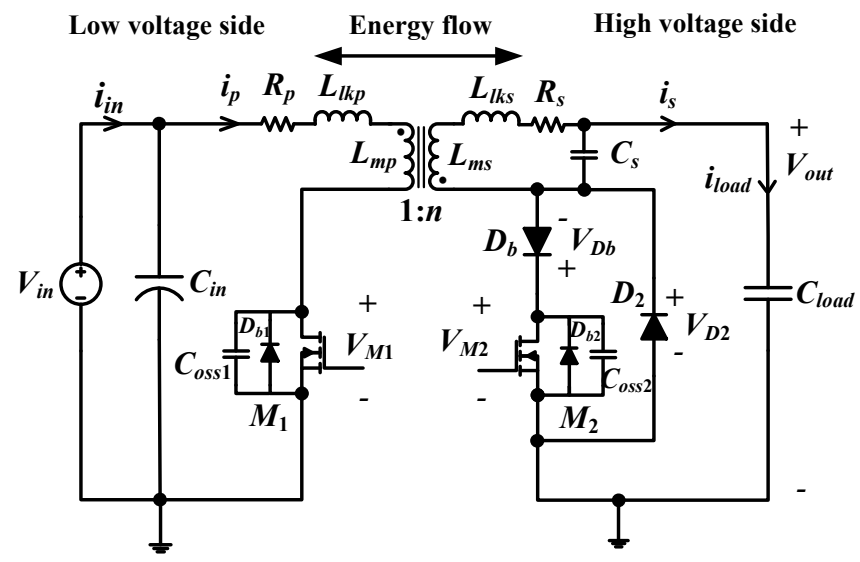

Fig. 4. Schematic of the high voltage bidirectional flyback converter for driving a high voltage capacitive load.

TABLE I. SPECIFICATIONS OF BIDIRECTIONAL FLYBACK CONVERTER

\begin{tabular}{c|c}
\hline \hline Parameter & Value \\
\hline \hline Input $V_{\text {in }}$ & $24 \mathrm{~V}$ \\
\hline Output voltage $V_{\text {out }}$ & $0-2.5 \mathrm{kV}\left(V_{o, \max }=2.5 \mathrm{kV}\right)$ \\
\hline Capacitance of the load $C_{\text {load }}$ & $400 \mathrm{nF}$ \\
\hline On time during charge process $t_{\text {onC }}$ & $9 \mu \mathrm{s}$ \\
\hline Target charging time $T_{\text {ch }}$ & $50 \mathrm{~ms}$ \\
\hline Maximum flux density $B_{\max C}$ & $0.35 \mathrm{~T}$ \\
\hline \hline
\end{tabular}

TABLE II. COMPONENTS USED IN THE CONVERTER

\begin{tabular}{|c|c|}
\hline Component & Value \\
\hline Primary MOSFET $M_{1}$ & $250 \mathrm{~V}, 25 \mathrm{~A}, 60 \mathrm{~m} \Omega[\mathrm{IPD} 600 \mathrm{~N} 25 \mathrm{~N} 3 \mathrm{G}]$ \\
\hline HV MOSFET $M_{2}$ & $\begin{array}{c}4.5 \mathrm{kV}, 200 \mathrm{~mA}, 750 \Omega \\
{[\mathrm{IXTA} 02 \mathrm{~N} 450 \mathrm{HV}] \text { and }} \\
4 \mathrm{kV}, 300 \mathrm{~mA}, 290 \Omega[\mathrm{IXTV} 03 \mathrm{~N} 400 \mathrm{~S} / \\
\text { IXTH03N400] }\end{array}$ \\
\hline $\mathrm{HV}$ diode $D_{b} / D_{2}$ & $5 \mathrm{kV}, 150 \mathrm{~mA}[\mathrm{SXF} 6525]$ \\
\hline
\end{tabular}

\section{A. Choice of turns ratio of the flyback transformer}

For the capacitor charging application, the turns ratio is selected based on the maximum charging voltage of the capacitive load $V_{o, \max }$. The typical voltage stress waveforms across MOSFETs $M_{1}, M_{2}$, and HV freewheeling diode $D_{2}$ are shown in Figs. 5a), 5b) and 5c), respectively.
1) Charge process: The minimum and maximum turns ratios, from secondary to primary of the flyback transformer during charge process can be calculated to meet the device breakdown voltage constraints.

The voltage stress across the primary MOSFET $M_{1}$ when turned off, should be less than its breakdown voltage $V_{B V M 1}$ (Fig. 5a)), so

$$
\left[V_{\text {in }}+\frac{\left[V_{o, \max }+V_{\text {onD2 } 2}\right]}{n}+V_{\text {leakP }}\right]<\beta_{1} V_{B V M 1}
$$

where $V_{\text {leakP }}$ is the increase in the drain voltage of primary MOSFET due to the leakage inductance $L_{l k P}$.

From (1), the transformer turns ratio

$$
n>n_{\min }
$$

where $n_{\min }$ is the minimum turns ratio needed, to charge the capacitive load to $V_{o, \max }$ and is given by
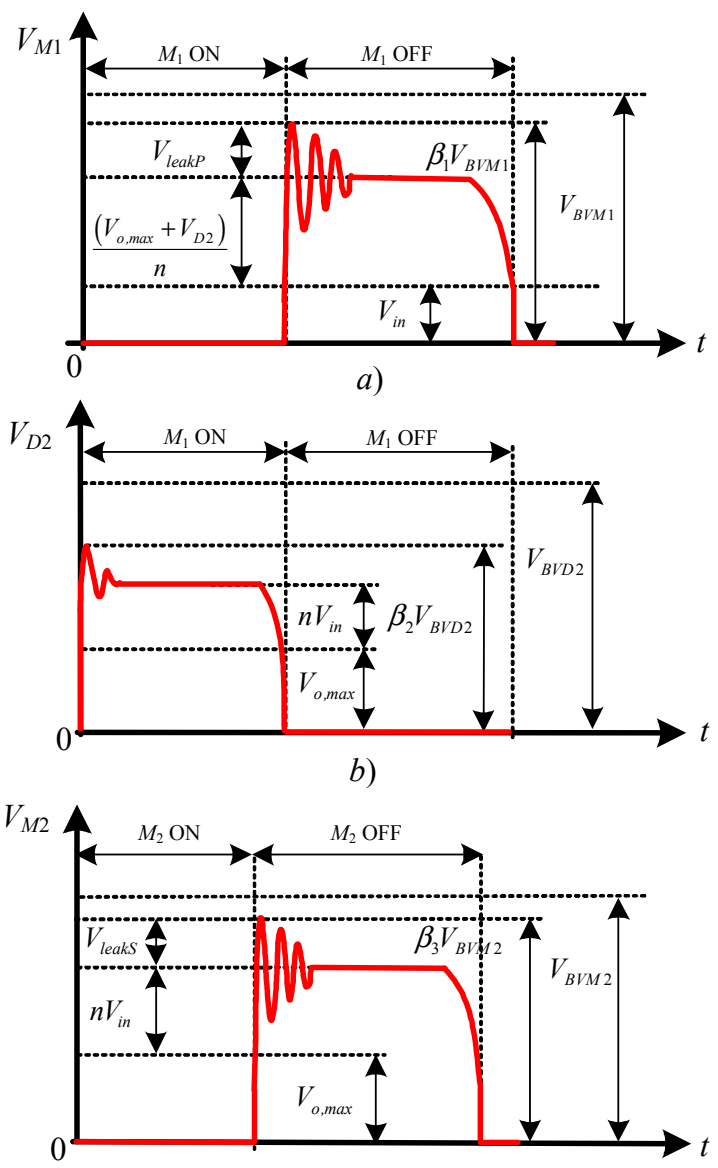

c)

Fig. 5. Voltage stress when target output voltage $\left(V_{o, \max }\right)$ is reached across a) $M_{1}$ during charge process $(\mathrm{BCM})$, b) $D_{2}$ during charge process (BCM), c) $M_{2}$ during discharge process $(\mathrm{BCM})$; $\mathrm{BCM}$ : Boundary Conduction 


$$
n_{\text {min }}=\frac{\left[V_{o, \max }+V_{o n D 2}\right]}{\left[\left(\beta_{1} V_{B V M 1}\right)-V_{\text {in }}-V_{\text {leakP }}\right]}
$$

For the given input specifications provided in Table I, by choosing $V_{\text {leak }}=70 \mathrm{~V}$ (this design value can be changed depending on the possible value of the leakage inductance referred to primary $L_{l k P}$ ), and choosing a margin factor of $\beta_{1}=0.9$ for a $250 \mathrm{~V}$ primary MOSFET (see Table II), with a high voltage diode drop $V_{o n D 2}=7 \mathrm{~V}$, the minimum turns ratio is $n_{\text {min }}=20$.

The voltage stress across the high voltage freewheeling diode $D_{2}$ when $M_{1}$ is turned on must be less than its breakdown voltage $V_{B V D 2}$ (Fig. $5 \mathrm{~b}$ )), so

$$
\left[V_{o, \max }+n V_{\text {in }}\right]<\beta_{2} V_{B V D 2}
$$

From (4), the transformer turns ratio

$$
n<n_{\max C}
$$

where $n_{\max C}$ is the maximum turns ratio needed for the charge process, and is given by

$$
n_{\max C}=\left[\frac{\beta_{2} V_{B V D 2}-V_{o, \max }}{V_{\text {in }}}\right]
$$

By choosing a margin factor of $\beta_{2}=0.8$ for a $5 \mathrm{kV}$ high voltage diode $D_{2}$, the maximum turns ratio is $n_{\max C}=62$. Since the charge and discharge processes are independent, the turns ratio during the discharge process needs to be calculated separately, and is described below.

2) Discharge process: The turns ratio limit of the flyback transformer during discharge process can be calculated from the breakdown voltage of the secondary HV MOSFET $M_{2}$. The voltage stress across $M_{2}$ when turned off should be less than its breakdown voltage $V_{B V M 2}$ (Fig. 5c)), so

$$
\left[V_{o, \max }+n V_{\text {in }}+V_{\text {leak } S}\right]<\beta_{3} V_{B V M 2}
$$

where $V_{\text {leaks }}$ is an increase in the drain voltage of $\mathrm{HV}$ MOSFET due to the leakage inductance $L_{l k s}$.

From (7), the transformer turns ratio

$$
n<n_{\max D}
$$

where $n_{\max D}$ is the maximum turns ratio needed for the discharge process, and is given by

$$
n_{\max D}=\left[\frac{\beta_{3} V_{B V M 2}-V_{o, \max }-V_{\text {leakS }}}{V_{\text {in }}}\right]
$$

Since $V_{B V M 2}<V_{B V D 2}$ (see Table II), the turns ratio $n$ should satisfy $20<n<48$, for $4.5 \mathrm{kV} \mathrm{HV} \mathrm{MOSFET}$, and $20<n<30$, for $4.5 \mathrm{kV}$ HV MOSFET, respectively. To avoid complexity and difficulty in winding several secondary turns in the transformer, the turns ratio $n$ is selected to be equal to 20 . However, it is up to the designer to choose a different turns ratio, different margin factors, and different rating low voltage MOSFET for this application.

\section{B. Design of primary and secondary turns}

The design methodologies for transformers and coupled inductors used in conventional switch-mode power supplies are well documented [21], [34]-[36]. For the bidirectional flyback converter, the primary and secondary turns are selected to avoid the saturation of the core during both charge and discharge modes. The converter operates with valley switching/BCM control during both charge and discharge processes [33].

1) Charge process: The number of primary turns needed during charge process is

$$
N_{p}=\frac{V_{\text {in }} t_{o n C}}{B_{\max C} A_{c}}
$$

The number of secondary turns needed is

$$
N_{s C}=N_{p} n
$$

By choosing an EF25 core (with N87 material) with $A_{c}=52$ $\mathrm{mm}^{2}$, and for the specifications shown in Table I, the primary and secondary turns become $N_{p}=12$ and $N_{s C}=240$, respectively.

2) Discharge process: The number of secondary turns needed during discharge process is

$$
N_{s D}=\frac{V_{o u t D} t_{o n D}}{B_{\max D} A_{c}}=\frac{n\left(V_{\text {in }}+\Delta V_{i n D}\right) t_{\text {off } D}}{B_{\max D} A_{c}}
$$

The same secondary turns $\left(N_{s}=N_{s C}=N_{s D}\right)$ should meet both (11) and (12). The input capacitance $C_{i n}=30 \mathrm{mF}$ is chosen, such that the voltage increment during the discharge process $\Delta V_{i n D}<2 \mathrm{~V}$.

\section{Selection of peak currents during charge and discharge processes}

1) Charge process: The expression for primary peak current to charge the $\mathrm{HV}$ capacitive load from $0 \mathrm{~V}$ to $V_{o, \max }$ in time $T_{c h}$ is [23], [34]

$$
I_{p p k C}=\frac{\left(2 n V_{\text {in }}+V_{o, \text { max }}\right) C_{\text {load }} V_{o, \max }}{\eta V_{\text {in }}\left(T_{c h}-T_{\text {delay }}\right)}
$$


For the given input specifications shown in Table I, for a turns ratio of $n=20$, by choosing a power efficiency $\eta=0.8$, and for a delay time $T_{\text {delay }}=5 \mathrm{~ms}$, the approximate primary peak current is $I_{p p k C}=4$ A.

The expression for maximum secondary peak current $I_{s p k C \text {, max }}$, to charge the HV capacitive load through HV diode $D_{2}$, when the converter is operating in a boundary conduction mode $(\mathrm{BCM})$ is

$$
I_{s p k C, \max }<\frac{2 I_{D 2}}{\left(1-D_{\text {onC }, \min }\right)}<\frac{2 I_{D 2}}{D_{\text {offC, } \max }}
$$

Equation (14) is derived based on the average current expression across $\mathrm{HV}$ diode $\mathrm{D}_{2}$ during the charge process. The maximum secondary peak charging current, when a $5 \mathrm{kV} \mathrm{HV}$ diode, with a rated current of $I_{D 2}=150 \mathrm{~mA}$ is used, and for a maximum off-duty cycle during charge process $D_{\text {offC,max }}=0.9$ is $I_{s p k C, \max }=333 \mathrm{~mA}$. This corresponds to a maximum primary peak current of $6.67 \mathrm{~A}$, for a turns ratio of $n=20$.

2) Discharge process: During the discharge process, since the output voltage decreases in each switching cycle, to discharge the load with constant peak current $i_{s p k D}$, the on-time $t_{\text {onD }}$ should increase in each switching cycle. The expression for maximum secondary peak current $I_{s p k D, \max }$, to discharge the $\mathrm{HV}$ capacitive load, through the series combination of high voltage diode $D_{b}$ and high voltage MOSFET $M_{2}$ (Fig. 4) is

$$
I_{s p k D, \max }<\frac{2 I_{S D}}{D_{\text {onD,max }}}
$$

where $I_{S D}$ is the average current in the secondary HV side during discharge process, and is given by:

$$
I_{S D}=\left\{\begin{array}{l}
I_{D b}, \text { if } I_{D b}<I_{M 2} \\
I_{M 2}, \text { if } I_{D b}>I_{M 2}
\end{array}\right.
$$

Since average current of $D_{b}$ is less than that of $M_{2}$, i.e., $I_{D b}<I_{M 2}$ (see Table II), $I_{S D}=I_{D b}$. The maximum secondary peak discharging current, for a maximum discharge on-duty cycle $D_{\text {on } D, \max }=0.8$ is $I_{s p k D, \max }=375 \mathrm{~mA}$. This corresponds to a maximum primary peak discharging current of $7.5 \mathrm{~A}$, for $n=20$.

\section{Design of primary magnetizing inductance}

1) Charge process: When the converter operates in BCM during charge process, selecting fixed on-time $t_{o n C}$ ensures constant peak current. In this case, the duty cycle and the switching frequency are maximum at the final switching cycle (where the output voltage is close to the maximum target output voltage $\left.\left(V_{o, \max }\right)\right)$, and minimum in the first switching cycle (where the output voltage is minimum or $0 \mathrm{~V}$ ). The expression for the primary magnetizing inductance needed for charge operation is

$$
L_{m p C}=\frac{V_{\text {in }} t_{o n C}}{I_{p p k C}}
$$

For $V_{i n}=24 \mathrm{~V}, t_{o n C}=9 \mu \mathrm{s}$, and $I_{p p k C}=4 \quad \mathrm{~A}$ the primary magnetizing inductance $L_{m p C}=54 \mu \mathrm{H}$.

2) Discharge process: When the converter operates in $\mathrm{BCM}$ during discharge process, selecting variable on-time $t_{\text {on } D}$ (since the output voltage is decreasing) ensures constant peak current. In this case, the duty cycle and the switching frequency are maximum at the first switching cycle (where the output voltage is close to the maximum target output voltage $\left.\left(V_{o, \max }\right)\right)$ and minimum in the final switching cycle (where the output voltage is close to minimum discharge voltage or $0 \mathrm{~V}$ ).

When the capacitive load transfers the energy back to the source, the input voltage slightly increases by $\Delta V_{\text {in } D}$. The magnitude of $\Delta V_{i n D}$ depends on the value of the input capacitance $C_{i n}$ used in the converter. The expression for the primary magnetizing inductance for discharge operation is

$$
L_{m p D}=\frac{\left(V_{i n}+\Delta V_{i n D}\right) t_{o f f D}}{I_{p p k D}}
$$

The same primary magnetizing inductance ( $L_{m p}=L_{m p C}=L_{m p D}$ ) should meet both (17) and (18).

From (10)-(12) and (17), (18), it can be concluded that, if the number of secondary turns $N_{s}=N_{s C}=N_{s D}$ and the magnetizing inductance $L_{m p}=L_{m p C}=L_{m p D}$ then, the flux density during the discharge process is

$$
B_{\max D}=\frac{I_{p p k D}}{I_{p p k C}} B_{\max C}=\frac{n I_{s p k D}}{I_{p p k C}} B_{\max C}
$$

The secondary discharge peak current $I_{s p k D}$ in any switching cycle limits the peak flux density $B_{\max D}$ during the discharge process. Hence, from (19) suppose if a secondary discharge peak current of $I_{s p k D}=200 \mathrm{~mA}$ is chosen, then the flux density during discharge process becomes (for $n=20$, $\left.I_{p p k C}=4 \mathrm{~A}, B_{\max C}=0.35 \mathrm{~T}\right) B_{\max D}=0.35 \mathrm{~T}$. Hence, the secondary discharge peak current $I_{s p k D}$ needs to be selected to avoid the core saturation during discharge operation.

\section{E. Selection of air-gap length $l_{g}$}

1) If the gap is put on the center leg of the core: The expression for the air-gap length is given by [21], [37]

$$
l_{g}=\left[\frac{\mu_{0} N_{p} I_{p p k C}}{B_{\max C}}-\frac{l_{m}}{\mu_{r}}\right]
$$

If $l_{g} \gg \frac{l_{m}}{\mu_{r}}$, the air-gap length becomes 


$$
l_{g}=\frac{\mu_{0} N_{p} I_{p p k C}}{B_{\max C}}
$$

where $l_{m}$ is the effective magnetic path length, and $\mu_{0}$ and $\mu_{r}$ are the permeability of vacuum and relative permeability of the ungapped core, respectively.

2) If the air-gap is put on the outer legs of the core: The expression for the air-gap length in this case is

$$
l_{g}=\frac{1}{2} \frac{\mu_{0} N_{p} I_{p p k C}}{B_{\max C}}
$$

In the practical high voltage transformer, an approximate air-gap length of $l_{g}=0.12 \mathrm{~mm}$ is provided in each outer leg of EF25 core. But, practically the transformer has a primary magnetizing inductance of $L_{m p}=38 \mu \mathrm{H}$, so when $9 \mu$ s constant on-time is used to drive $M_{1}$, peak current $I_{p p k C}$ becomes 5.68 $\mathrm{A}$, which is less than the maximum calculated value of $6.6 \mathrm{~A}$.

\section{EXPERIMENTAL RESULTS}

The experimental prototype of the bidirectional flyback converter with E25 transformer and $4 \mathrm{kV}$ through hole MOSFET (TO-247) is shown in Fig. 6. The experimental results showing a single bidirectional charge and discharge cycle at $2.42 \mathrm{kV}$ output voltage is provided in Fig. 7. Figure 8 provides the experimental result when the converter is continuously charged and discharged at $1.8 \mathrm{kV}$ output voltage. As shown in Fig. 8, when a diode is placed between the input dc supply and the input capacitor $C_{i n}$, during the charge process the input voltage slightly drops, and during the discharge process the input voltage slightly increases, as expected.

A sectioned EF25 bobbin with 4 sections is used for the flyback transformer. Sectioning the transformer significantly reduces the self-capacitance of the high voltage winding [32]. A $0.5 \mathrm{~mm}$ triple isolated (TEX-E) solid wire is used for the primary winding, and $0.1 \mathrm{~mm}$ normal single insulated solid wire is used for the secondary winding.

The measured flyback transformer parameters (using Agilent 4294A Impedance analyzer) are provided in Table III. Temperature measurements are performed to verify the reliable operation of the proposed design. During the thermal measurements, instead of $250 \mathrm{~V}, 25 \mathrm{~A}, 60 \mathrm{~m} \Omega$ [IPD600N25N3 G] MOSFET, another $200 \mathrm{~V}, 600 \mathrm{~m} \Omega, 5$ A (IRFR220N)

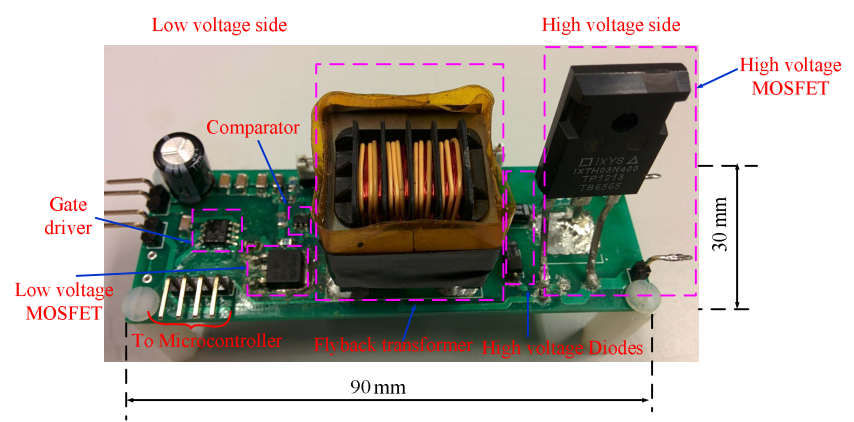

Fig. 6. Experimental prototype of the bidirectional flyback converter.

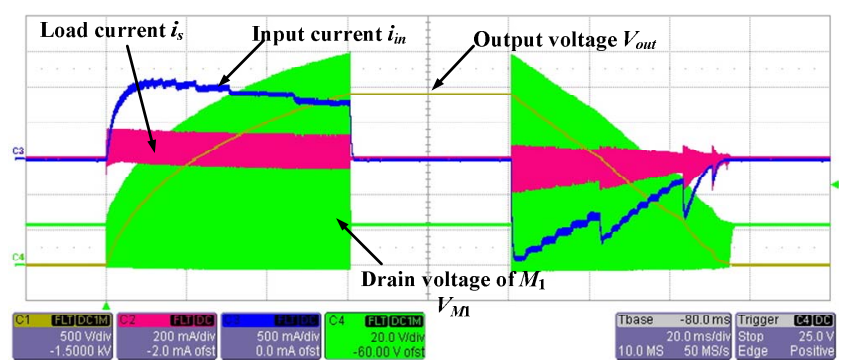

Fig. 7. Experimental waveforms showing the bidirectional operation at $2.42 \mathrm{kV}$ output voltage. The $24 \mathrm{~V}$ dc source and the input capacitor are directly connected.

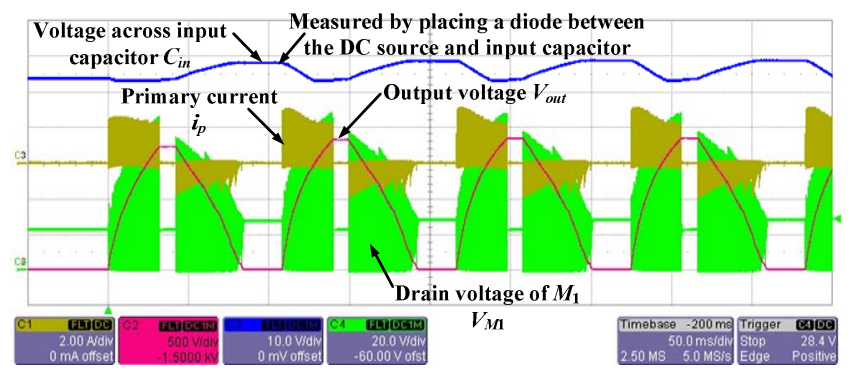

Fig. 8. Continuous bidirectional cycles at $1.8 \mathrm{kV}$ output voltage. A diode is placed between the $24 \mathrm{~V}$ dc source and the input capacitor.

MOSFET is used. Figure 9 provides the steady-state thermal profile of the converter when it is charged and discharged continuously for $30 \mathrm{~min}$, at $2 \mathrm{kV}$ output voltage. The test was performed without any delay between the charge and discharge cycles. The maximum temperature rise was across the low voltage MOSFET, because of the conduction loss due to its high on-resistance, the temperature across the flyback transformer was $61{ }^{\circ} \mathrm{C}$. Furthermore, it is expected that the temperature across the transformer will be higher than $10^{\circ} \mathrm{C}$, if the converter is continuously charged $(0 \mathrm{~V} \rightarrow 2.5 \mathrm{kV})$ and discharged $(2.5 \mathrm{kV} \rightarrow 0 \mathrm{~V})$ at $2.5 \mathrm{kV}$. Another test was performed by putting a delay time of $100 \mathrm{~ms}$ between the charge and discharge cycles, the temperature profile is shown in Fig. 10. In this case, the maximum temperature across the transformer is $\sim 46^{\circ} \mathrm{C}$, due to the low average power across it.

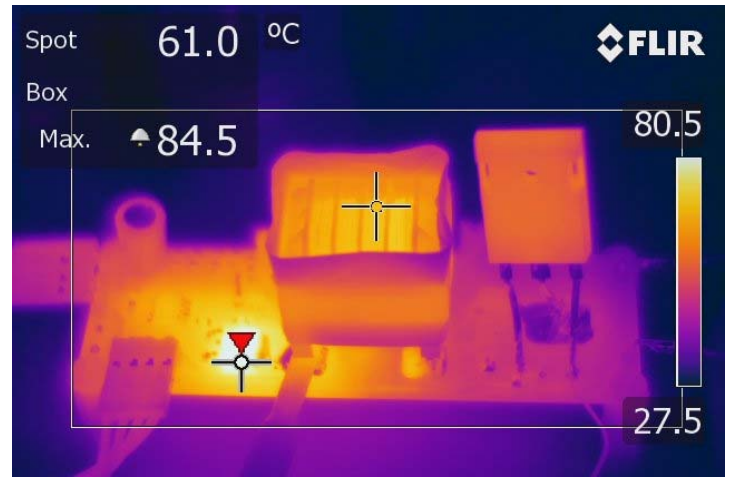

Fig. 9. Steady-state temperature measurement, when the converter is continuously charged and discharged (without any delay between the cycles) from $0 \mathrm{~V}$ to $2 \mathrm{kV}$, and vice versa, when $200 \mathrm{~V}, 600 \mathrm{~m} \Omega, 5 \mathrm{~A}$ (IRFR220N) low voltage MOSFET is used. 


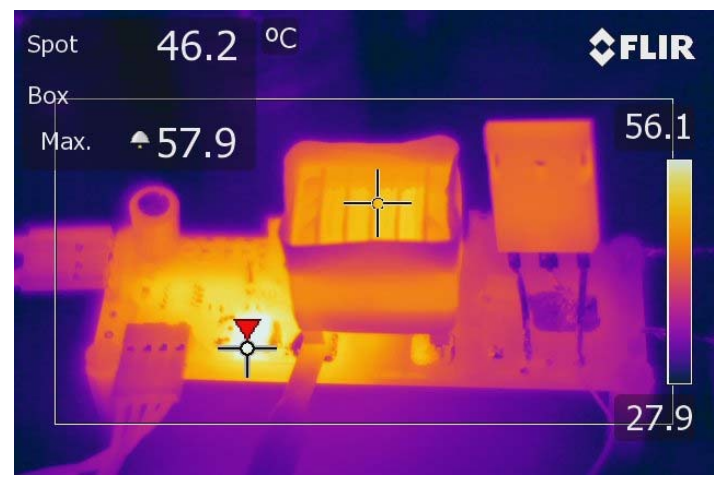

Fig. 10. Steady-state temperature measurement, when the converter is continuously charged and discharged (without $100 \mathrm{~ms}$ delay between the cycles) from $0 \mathrm{~V}$ to $2 \mathrm{kV}$, and vice versa, when IRFR220N $(200 \mathrm{~V}, 600$ $\mathrm{m} \Omega, 5$ A) low voltage MOSFET is used.

Since the load is purely capacitive, the converter efficiency is defined as energy efficiency, instead of normal power efficiency. The charge and discharge energy efficiency measurement [30] results are provided in Table IV. During the charge process the output energy is the energy stored in the load capacitor, and the input energy is obtained by integrating the input charge current and multiplying it with the input voltage. During the discharge process, the input energy is the energy stored in the load capacitor, and the output energy is obtained by integrating the input discharge current and multiplying it with the input voltage. All components shown in Table II are used during the energy efficiency measurements. As explained earlier, the converter operates with valley switching control during charge and discharge operations. The charge and discharge efficiencies are $89.2 \%$ and $83.4 \%$, respectively. The reasons for the lower discharge energy efficiency are explained in [33].

TABLE III. FLYBACK TRANSFORMER PARAMETERS

\begin{tabular}{c|c}
\hline \hline Parameter & Value \\
\hline \hline Core used / material used & EF25 / N87 \\
\hline Type of bobbin (coil former) & $\begin{array}{c}\text { Sectioned with } \\
4 \text { sections }\end{array}$ \\
\hline Number of primary $N_{p} /$ secondary turns $N_{s}$ & $12 / 240$ \\
\hline $\begin{array}{c}\text { Primary } L_{m p} / \text { secondary magnetizing } \\
\text { inductance } L_{m s}\end{array}$ & $38 \mu \mathrm{H} / 15.2 \mathrm{mH}$ \\
\hline $\begin{array}{c}\text { Leakage inductance referred to primary } L_{l k p} / \\
\text { secondary } L_{l k s}\end{array}$ & $450 \mathrm{nH} / 185 \mu \mathrm{H}$ \\
\hline Self-capacitance of secondary winding $C_{s}$ & $5 \mathrm{pF}$ \\
\hline Dc resistance of primary $R_{p} /$ secondary $R_{s}$ & $50 \mathrm{~m} \Omega / 10.5 \Omega$ \\
\hline \hline
\end{tabular}

TABLE IV. ENERGY EFFICIENCY AT $2.4 \mathrm{KV}$ OUTPUT VOLTAGE

\begin{tabular}{c|c|c|c}
\hline \hline $\begin{array}{c}\text { Type of } \\
\text { mode }\end{array}$ & $\begin{array}{c}\text { Input } \\
\text { energy (J) }\end{array}$ & $\begin{array}{c}\text { Output } \\
\text { energy (J) }\end{array}$ & $\begin{array}{c}\text { Energy } \\
\text { efficiency (\%) }\end{array}$ \\
\hline \hline Charge & 1.29 & 1.15 & $\begin{array}{c}89.2 \text { (to charge from 0 } \\
\text { V to } 2.4 \mathrm{kV})\end{array}$ \\
\hline Discharge & 1.15 & 0.96 & $\begin{array}{c}83.4 \text { (to discharge } \\
\text { from } 2.4 \mathrm{kV} \text { to } 0 \mathrm{~V})\end{array}$ \\
\hline \hline
\end{tabular}

\section{CONCLUSIONS}

This paper describes the detailed power stage design of the high voltage bidirectional flyback converter for driving a dielectric electro active polymer (DEAP) based capacitive actuator. Experimental results are provided to show the bidirectional operation (charge and discharge) of the high voltage converter. Even though the flyback transformer is designed for a high peak charging flux density of $0.35 \mathrm{~T}$, thermal measurement results show that the maximum temperature across the transformer is $61{ }^{\circ} \mathrm{C}$. Therefore, for a high voltage capacitor charge and discharge applications it is possible to minimize the number of transformer turns on the secondary high voltage side, by choosing a high flux density.

Energy efficiency measurements are provided for the charge and discharge modes using the proposed design. For driving the capacitive load at $2.4 \mathrm{kV}$, the converter attains charge and discharge energy efficiencies of $89.2 \%$ and $83.4 \%$, respectively. It is easy to make three similar converters with the same design for driving the DEAP incremental actuator, which has an enormous potential in the automotive industry. By optimizing the flyback transformer design, it is possible to increase the power density of the high voltage driver, so that it can be easily placed in the EVs. The research on the DEAP material is still on-going, and in the future it is expected that the operating voltage ranges of the DEAP actuators may be reduced to $1.5-2 \mathrm{kV}$ from the current range $2-2.5 \mathrm{kV}$.

\section{REFERENCES}

[1] Y. Bar-Cohen, "Electroactive Polymer [EAP] Actuators as Artificial Muscles: Reality, Potential, and Challenges," 2nd ed. Washington, DC: SPIE, 2004

[2] F. Carpi, D. DE Rossi, R. Kornbluh, R. Pelrine, P. Sommer-Larsen, Eds, "Dielectric Elastomer As Electromechanical Transducers," Amsterdam, The Netherlands: Elsevier, 2008.

[3] R. E. Pelrine, R. D. Kornbluh, Q. Pei, J. P. Joseph, "High-speed electrically actuated elastomers with strain greater than $100 \%$," Science, vol. 287, pp. 836-839, 2000.

[4] Danfoss PolyPower, Denmark, Online available: http://www.polypower.com/ [accessed 20 Oct. 2014].

[5] LEAP Technology, Denmark, Online available: http://leaptechnology.com/ [accessed 20 Oct. 2014].

[6] M. Tryson, H. E. Kiil, M. Benslimane, "Powerful tubular core free dielectric electro active polymer (DEAP) push actuator," in Proc. SPIE, vol. 7287, 2009.

[7] R. Sarban, B. Lassen, M. Willatzen, "Dynamic Electromechanical Modeling of Dielectric Elastomer Actuators With Metallic Electrodes," IEEE/ASME Trans. Mechatronics, vol. 17, no. 5, pp. 960-967, Oct. 2012.

[8] R. D. Kornbluh, R. Pelrine, Q. Pei, R. Heydt, S. Stanford, S. Oh, J. Eckerle, "Electroelastomers: applications of dielectric elastomer transducers for actuation, generation, and smart structures," in Proc. SPIE, vol. 4698, pp. 254-270, 2002.

[9] Q. Pei, R. Pelrine, S. Stanford, R. D. Kornbluh, M. S. Rosenthal, K Meijer, R. J. Full, "Multifunctional electroelastomer rolls and their application for biomimetic walking robots," in Proc. SPIE, vol. 4698, 2002.

[10] I. A. Anderson, T. A. Gisby, T. G. McKay, B. M. O’Brien, E. P. Calius, "Multi-functional dielectric elastomer artificial muscles for soft and smart machines," Journal of Applied Physics, 112, 041101, 2012.

[11] K. Jung, J. C. Koo, J. -do Nam, Y. K. Lee, H. R. Choi, “Artificial annelid robot driven by soft actuators," Journal of Bioinspiration and Biomimetics, vol. 2, pp. S42-S49, 2007. 
[12] I. A. Anderson, T. C. H. Tse, T. Inamura, B. M. O’Brien, T. McKay, T. Gisby, "A soft and dexterous motor," Journal of Applied Physics, 98, 123704, 2011

[13] A. T. Conn, A. D. Hinitt, P. Wang, "Soft segmented inchworm robot with dielectric elastomer muscles," in Proc. SPIE, Electroactive Polymer Actuators and Devices (EAPAD), vol. 9056, pp. 90562L, 2014.

[14] F. Carpi, R. Kornbluh, P. Sommer-Larsen, G. Alici, "Electroactive polymer actuators as artificial muscles: are they ready for bioinspired applications?," Journal of Bioinspiration and Biomimetics, vol. 6 (4), 2011.

[15] Siemens website, online available [accessed 29 Oct. 2014]: http://www.siemens.com/innovation/en/publikationen/publications pof/ pof spring 2006/motors articles/future motors.htm

[16] Helix Linear Technologies website, online available [accessed 29 Oct. 2014]: http://blog.helixlinear.com/bid/307529/How-a-Small-ElectricActuator-Operates-Automotive-Headlights.

[17] The University of Sheffield website, online available [accessed 29 Oct. 2014]: http://www.sheffield.ac.uk/research/impact/stories/fce/7.

[18] VDO global website, online available [accessed 29 Oct. 2014]: http://www.vdo.com/generator/www/com/en/vdo/main/products solutio ns/cars/replacement_parts/engine_actuators/digital_linear_actuators/digi tal linear_actuators en.html.

[19] VDO global website, online available [accessed 29 Oct. 2014]: http://www.vdo.com/generator/www/com/en/vdo/main/products solutio ns/cars/replacement parts/actuators for_central locking_systems/actuat ors_for_central locking_systems_en.html.

[20] P. Thummala, Z. Zhang, M. A. E. Andersen, S. Rahimullah, "Dielectric electro active polymer incremental actuator driven by multiple highvoltage bi-directional DC-DC converters," in Proc. IEEE ECCE USA, pp. 3837-3844, 15-19 Sept. 2013.

[21] R. W. Erickson, D. Maksimovic, "Fundamentals of Power Electronics," $2^{\text {nd }}$ ed. New York: Springer, 2001.

[22] H. K. Sang, D. Maksimovic, I. Cohen, "Efficiency Optimization in Digitally Controlled Flyback DC-DC Converters Over Wide Ranges of Operating Conditions," IEEE Trans. Power Electronics, vol. 27, no. 8, pp. 3734-3748, Aug. 2012.

[23] N. O. Sokal, R. Redl, "Control algorithms and circuit designs for optimal flyback-charging of an energy storage capacitor (e.g., for flash lamp or defibrillator)," IEEE Trans. Power Electronics, vol. 12, no. 5, pp. 885-894, Sep. 1997.

[24] J. Elmes, C. Jourdan, O. Abdel-Rahman, I. Batarseh, "High-Voltage, High-Power-Density DC-DC Converter for Capacitor Charging Applications," in Proc. IEEE APEC, pp. 433-439, 2009.

[25] S. K. Chung, H. B. Shin, "High-voltage power supply for semi-active suspension system with ER-fluid damper," IEEE Trans. Vehicular Technology, vol. 53, no. 1, pp. 206- 214, Jan. 2004.

[26] T. Bhattacharya, V. S. Giri, K. Mathew, L. Umanand, "Multiphase Bidirectional Flyback Converter Topology for Hybrid Electric Vehicles," IEEE Trans. Industrial Electronics, vol. 56, no. 1, pp. 78-84, Jan. 2009.

[27] G. Chen, Y.-S. Lee, S. Y. R. Hui, D. Xu, Y. Wang, "Actively clamped bidirectional flyback converter," IEEE Trans. Industrial Electronics, vol. 47, no. 4, pp. 770-779, Aug. 2000.

[28] F. Zhang, Y. Yan, "Novel Forward-Flyback Hybrid Bidirectional DCDC Converter," IEEE Trans. Industrial Electronics, vol. 56, no. 5, pp. 1578-1584, May 2009.

[29] T. Andersen, M. S. Rødgaard, O. C. Thomsen, M. A. E. Andersen, "Low voltage driven dielectric electro active polymer actuator with integrated piezoelectric transformer based driver," in Proc. SPIE EAPAD, vol. 7976, p. 79762N, 2011.

[30] P. Thummala, Z. Zhang, M. A. E. Andersen, "High Voltage Bidirectional Flyback Converter for Capacitive Actuator," in Proc. IEEE EPE, pp. 3-6 Sept. 2013.

[31] P. Thummala, H. Schneider, Z. Zhang, A. Knott, M. A. E. Andersen, "Optimization of a bi-directional flyback converter for a high voltage capacitor charging application," in Proc. IEEE APEC, pp. 2556-2563, 16-20 March 2014.
[32] H. Schneider, P. Thummala, L. Huang, Z. Ouyang, A. Knott, Z. Zhang, M. A. E. Andersen, "Investigation of transformer winding architectures for high voltage capacitor charging applications," in Proc. IEEE APEC, pp. 334-341, 16-20 March 2014.

[33] P. Thummala, D. Maksimovic, Z. Zhang, M. A. E. Andersen, "Digital control of a high-voltage $(2.5 \mathrm{kV})$ bidirectional DC-DC converter for driving a dielectric electro active polymer (DEAP) based capacitive actuator," in Proc. IEEE ECCE USA, pp. 3435-3442, 14-18 Sept. 2014.

[34] LT3751 datasheet, "High voltage capacitor charger controller with regulation," Linear Technology Corporation, USA, Online available: http://cds.linear.com/docs/en/datasheet/3751fc.pdf [accessed 16 Oct. 2014].

[35] C. W. T. McLyman, Transformer and Inductor Design Handbook, $3^{\text {rd }}$ Ed., New York: Marcel Dekker, 2004.

[36] W. G. Hurley, W. H. Wolfle, Transformers and Inductors for Power Electronics: Theory, Design and Applications, $1^{\text {st }}$ Ed., John Wiley and Sons Ltd., 2013.

[37] M. Kazimierczuk, High-frequency magnetic components, $2^{\text {nd }}$ Ed., John Wiley and Sons Ltd., 2014. 